\title{
The Effect of Grazing Dairy Cattle with Alfalfa (Medicago sativa L.) on Milk Minerals, CLA, and Fatty Acid Levels
}

\author{
Mustafa Güçlü SUCAK ${ }^{1 *}$, Ahmet ÖZKAYA², Oğuz AĞYAR¹, Uğur KARA³, Selma BÜYÜKILIÇ BEYZİ', \\ Zeynep ŞAHAN5 ${ }^{5}$ Uğur SERBESTER ${ }^{6}$
}

${ }^{1}$ Department of Veterinary, Kahta Vocational School, Adiyaman University, 02440, Kahta, Adyaman, Turkey ${ }^{2}$ Department of Chemistry, Faculty of Science and Letters, Adryaman University, 02040, Adryaman, Turkey ${ }^{3}$ Eastern Mediterranean Agricultural Research Institute, Adana, Turkey

${ }^{4}$ Department of Animal Science, Seyrani Agricultural Faculty of Erciyes University, 38280, Melikgazi, Kayseri, Turkey ${ }^{5}$ Department of Field Crops, Kahta Vocational School, Adryaman University, 02440, Kahta, Adıyaman, Turkey ${ }^{6}$ Department of Animal Science, Faculty of Agricultural, Çukurova University, 01330 Balcalı, Sarç̧am, Adana, Turkey

ORCID ID: Mustafa Güçlü SUCAK: https:/ / orcid.org/0000-0001-6147-470X; Ahmet ÖZKAYA: 0000-0002-0173-3084; Oğuz AĞYAR: https:/ / orcid.org/0000-0002-6107-894X; Uğur KARA: https:/ / orcid.org/0000-0002-7977-6826; Selma BÜYÜKILIÇ BEYZİ: https:// orcid.org/0000-0002-4622-0645; Zeynep ŞAHAN: https://orcid.org/0000-0001-7878-5117; Uğur SERBESTER: https://orcid.org/00000003-4460-3797

Received: 20.02.2020 Accepted: $31.03 .2020 \quad$ Published online: 03.04.2020 Issue published: 29.06 .2020

Abstract: Grazing Alfalfa in the nutrition of ruminant animals has been increasing day by day. In this study, it was aimed to compare milk mineral and fatty acid levels of cows fed with Total Ration Mix (TMR) and cows fed with fresh alfalfa and commercial concentrate feed ( $2.7 \mathrm{Mcal} / \mathrm{kg} \% 21$ crude protein). 24 Holstein cows were divided into two groups. The first group (TMR Group) was fed with TMR. TMR content involves barley, commercial concentrate feed (2.7 Mcal/ kg \% $21 \mathrm{crude}$ protein), corn silage, straw, and dry alfalfa. The second group (Aflalfa Group) was mainly fed with artificial alfalfa pasture as well as barley and commercial concentrate feed. The element and fatty acid levels of alfalfa plant samples from artificial alfalfa pasture and milk samples were determined by using Induced Coupled Plasma Mass Spectrophotometry (ICP-MS) and Gas Chromatography (GC) devices. TMR Group's milk calcium (Ca), phosphorus (P), and zinc (Zn) levels were found to be lower than cow's milk in Alfalfa Group. It was observed that while the caprylic acid (8:0) and myristic acid (14:0) levels of the Alfalfa Group were lower than the TMR Group; myristoleic acid (14:1), cis-11-eicosenoic acid (20:1n9c), gamma-linolenic acid (18:3n6), cis-8,11,14-eicosatrienoic acid (20:3n6), cis-5, 8,11,14,17-eicosapentaenoic acid (20:5n3), KLAc9t11 and KLAt10c12 fatty acid levels were high $(\mathrm{p}<0.05)$. Alpha-linolenic acid $(18: 3 \mathrm{n} 3) 14.482 \%$, linoleic acid $(18: 2 \mathrm{n} 6 \mathrm{c}) 4.528 \%$, palmitic acid $(16: 0) 9.551 \%$ and stearic acid (18:0) $29.788 \%$ were found to be major fatty acids in alfalfa plants. The alfalfa plant was determined at levels of Ca $8167 \mathrm{mg} / \mathrm{kg}, \mathrm{P} 951 \mathrm{mg} / \mathrm{kg}$, manganese (Mn) $14.16 \mathrm{mg} / \mathrm{kg}, \mathrm{Zn} 4.25 \mathrm{mg} / \mathrm{kg}$ and iron (Fe) $143 \mathrm{mg} / \mathrm{kg}$. In this study, a high rate of 18:3n 3 fatty acids were detected in the alfalfa plant content. For further studies, we think that this study may be a pioneer in the research on the effects of 18:3n3 fatty acid on CLA metabolism in rumen biohydrogenation of cows. As a result, alfalfa is considered to have positive effects on element and fatty acid levels.

Keywords: Cow Milk, TMR, 18:3n3 Fatty Acid, Rumen Biohydrogenation, ICP-MS.

\section{Laktasyondaki Süt Sığırlarına Yapay Yonca (Medicago sativa L.) Merasında Otlatmanın Süt Mineralleri, KLA ve Yağ Asit Düzeylerine Etkisi}

Öz: Ruminant hayvanların beslenmesinde taze yonca kullanımı gün geçtikçe artmaktadır. Bu çalışmada, Toplam Rasyon Karışımı (TMR) ile beslenen inekler ile taze yonca ve ticari kesif yem ( $2.7 \mathrm{Mcal} / \mathrm{kg} \% 21 \mathrm{ham}$ proteinli) beslenen ineklerin süt mineral ve yağ asit düzeylerinin karşılaştırılması amaçlanmıştır. 24 adet Holstein ineği iki gruba ayrıldı. Birinci grup (TMR Grubu) TMR ile beslendi. TMR içeriği; arpa, ticari kesif yemi, mısır silajı, saman, kuru yonca otundan oluşmaktadır. İkinci grup (Yonca Grubu) ise temel olarak yapay yonca merası ile beslenmesinin yanı sıra arpa ve ticari kesif yemle beslendi. İnek süt örnekleri, yapay yonca merasından toplanan yonca bitkisinin element ve yağ asit düzeyleri, İndüklenmiş Eşleşmiş Plazma Kütle Spektrofotometresi (ICP-MS) ve Gaz Kromatografisi (GC) cihazları kullanılarak belirlenmiştir. TMR Grubu'nun süt kalsiyum $(\mathrm{Ca})$, fosfor $(\mathrm{P})$ ve çinko $(\mathrm{Zn})$ düzeyleri Yonca Grubu'ndaki inek sütlerinden düşük çıktığı tespit edildi. Yonca Grubu'nun süt yağ asitlerinden kaprylik asit (8:0) ve myristik asit (14:0) düzeyleri TMR Grubu' na göre düşük çıkarken; myristoleik asit (14:1), cis-11-eicosenoik asit (20:1n9c), gamma-linolenik asit (18:3n6), cis-8,11,14-eikosatrienoik asit (20:3n6), cis-5,8,11,14,17eicosapentaenoik asit (20:5n3), KLAc9t11 ve KLAt10c12 yă̆ asit düzeyleri yüksek çıktı̆̆ gözlendi ( $p<0.05)$. Yonca bitkisinde majör yağ asidi olarak alfa-linolenik asit (18:3n3) \%14.482, linoleik asit (18:2n6c) \%4.528, palmitik asit (16:0) \%9.551 ve stearik asit (18:0) \%29.788 olarak tespit edilmiştir. Yonca bitkisi Ca $8167 \mathrm{mg} / \mathrm{kg}, \mathrm{P} 951 \mathrm{mg} / \mathrm{kg}$, mangan (Mn) $14.16 \mathrm{mg} / \mathrm{kg}$, Zn 4.25 $\mathrm{mg} / \mathrm{kg}$ ve demir $(\mathrm{Fe}) 143 \mathrm{mg} / \mathrm{kg}$ düzeylerinde belirlendi. Bu çalışmada, yonca bitkisi içeriğinde yüksek oranda 18:3n3 yağ asidi tespiti yapıldı. İleriki çalışmalar için, ineklerin Rumen biyohidrojenasyonunda 18:3n3 yağ asidinin KLA metabolizması üzerine etkilerini konu alacak araştırmalarda, bu araştırmanın öncü olabileceğini düşünmekteyiz. Sonuç olarak, yonca ile beslenen ineklerin element ve yağ asit düzeylerine pozitif yönde etkileri olduğu düşünülmektedir.

Anahtar kelimeler: İnek sütü, TMR, 18:3n3 Yağ Asidi, Rumen Biohidrojenasyon, ICP-MS. 


\section{Giriş}

İnsanların günlük diyetlerinde süt ve süt ürünleri yoğun olarak yer almaktadır. Dünyada inek, keçi, koyun, manda ve deve gibi hayvanların sütleri kullanılmakta olup en yaygın olarak inek sütü tüketilmektedir. Süt içeriğinde laktoz, kazein, protein, vitaminler, mineraller ve yağ asitleri bulunmaktadır. Sütün insan metabolizması üzerine birçok yararlı etkileri vardır. Özellikle kardiyovasküler hastalıkların, kanserin, diyabetin ve obezite gibi hastalıkların önlenmesinde önemli rollerinin olduğu bildirilmiştir (Claeys et al., 2013; Claeys et al., 2014; Pereira, 2014). Minerallerin insan metabolizmasinda önemli görevleri vardır. Özellikle de enzimatik reaksiyonların işlevlerinde, immünolojik reaksiyonlarda, enfeksiyon hastalıkların tedavisinde ve cilt hastalıklarının iyileştirilmesi üzerinde pozitif etkileri olduğu rapor edilmiştir (Chaturvedi, Shrivasta, \& Upreti, 2004; Selvaraju, Raman, Narayanaswamy, Valliappan, \& Baskaran, 2009; Emsley, 2011).

İnsanlar besinlerle metabolizmaya aldıkları yağ asitlerinden olan doymamış yağ asitleri bağışıklık sistemini güçlendirmektedir. Doymamış yağ asitleri, beyin fonksiyonlarının düzenlenmesinde ve hücre zarı yapısının korunmasında önemli rolleri vardır. Ayrıca, doymamış yağ asitlerinin birçok hastalık üzerinde iyileştirici yönde pozitif etkilerinin de olduğu rapor edilmiştir (Steffens \& Wirth, 2005; Li \& Hu, 2009; De Lorgeril et al., 1999; Appel, Miller, Seidler, \& Whelton, 1993). Doymamış yağ asitlerinden olan konjugelinoleik asit (KLA), linoleik asidin (18:2n6c) kimyasal izomerleri şeklindedir. Bu izomer yağ asitleri cis9, trans-11 ve trans-10, cis-12 şeklinde bulunmakta olup insan metabolizmasinda önemli miktarda sentezlenmediğinden dolayı et ve süt ürünlerinden temin edilmektedir. KLA ile ilgili yapılan birçok çalışmada bu maddelerin antikanser, antioksidan, antidiyabetik, antiobezite, antiaterojenik ve vücut yağını azaltıcı etkilerinin olduğu bildirilmiştir (Wang \& Jones, 2004; İnanç, 2006; Wahle, Heys, \& Rotondo, 2004; Tanaka, 2005; Kurban \& Mehmetoğlu, 2006; Sezer, Aksoy, Üstün, \& Tüter, 2011; Yücel, Özçimen, \& Tatlı, 2011; Kelly, 2001).

Ülkemizdeki süt besiciliğinde Tam Karışım Yem (TMR) ile hayvanların beslenme modeli yaygındır. Bu modelde yem içeriğinde kullanılan kaba yemler kuru ot ve anaerobic ortamda hazırlanmış silaj gibi fermente yemlerden oluşmaktadır. Otların kurutulması ya da fermantasyon yoluyla silaj yapılması esnasında taze otun içermiş olduğu yağ asitlerinde özellikle alfa-linolenik (18:3n3) asit miktarında yarıya yakın oranda kayıp meydana gelmektedir. Bu da, sütün yağ asit profilini önemli düzeyde etkileyebilmektedir (Tanaka, 2005).

Büyükbaş ve küçükbaş hayvanların beslenmesinde yemin niteliği ve miktarı oldukça önemlidir. Meralar, bu konuda, sahip oldukları bitki çeşitliliği ve miktarları bakımından hayvan beslenmesinde önemli bir yer tutmaktadır. Arjantin, Avustralya ve Yeni Zelanda gibi ülkelerde taze yoncadan oluşturulmuş yapay meralarda çiftlik hayvanları beslenmekte iken, kuru ot veya düşük nemli ot silajı (haylage) ile hayvan beslenmesi ise Amerika ve bazı ülkelerde tercih edilmektedir. Türkiye'de ise çiftlik hayvanlarının yapay yonca merasında beslenme modeli yaygın değildir. Taze yonca vitamin ve mineral içeriği bakımından zengin olduğundan, aşırı beslenen hayvanların metabolizmasında meteorismus durumu gelişebilir. Bu metabolik durum yüzünden Türkiye'deki birçok yetiştiricinin yapay yonca merasında hayvan besleme modeli tercihinde tereddütler oluşmaktadır. $\mathrm{Bu}$ yaygın durumun aşılmasında, TMR ile beslenen hayvanların, taze yonca ile beslenme sistemine geçerken adaptasyon dönemi büyük önem arz etmektedir (Volesky \& Anderson, 2010; Castillo et al., 2006). Arjantin gibi yıl boyu iklimin 1lımlı ve yağışlı geçtiği ülkelerde oluşturulan bu tarzdaki yapay yonca meraların sürekliliği vardır. Böylece meraların rotasyonlu olarak sürekli otlatılabilmeleri mümkün olabilmektedir. Araştırıcılar bu besleme sistemi ile $20 \mathrm{~kg} /$ gün süt verimi ve günlük yem tüketiminin yarısını yapay yonca merasından karşılayan bir süt ineği için otlatma kapasitesinin yaklaşık $74 \mathrm{~m}^{2}$ yapay mera alanının yeterli olduğunu bildirmişlerdir (Cangiano, Castillo, Guerrero, \& Putnam, 2008).

Bu çalışmada ise, Türkiye'nin Adryaman ilinde yetiştirilen süt ineklerinin sadece kış süresince atıl bırakılan yapay yonca merasında otlatılması yapılarak, bu tür bir besleme modelinde ineklerin süt yağ asitleri ve süt mineralleri düzeyleri üzerindeki etkileri araştırılmıştır.

\section{Materyal ve Yöntem}

\subsection{Hayvan ve süt materyalleri}

Çalışmada ikinci laktasyon döneminde ve ortalama canlı ağırlığ1 $509 \pm 21 \mathrm{~kg}$ olan 24 adet Holstein cinsi inek kullanıldı. İnekler Adıyaman ili, Kahta ilçesine bağlı Ortanca mevkiinde bulunan Öztürk Tarım işletmesinden sağlanmıştır. İnekler iki gruba ayrılmıştır. Birinci gruba TMR yemi padoklarda verildi. İkinci gruba ise kaba yemi yapay yonca merasından, kesif yemini ise padoklarda verilmiştir (Tablo 1). Her iki grubun su tüketimi ad libitum olarak padoklardan alınması sağlanmıştır.

Yonca Grubu ineklerin yapay yonca merasından beslenme alışkanlığı kazanması için iki hafta adaptasyon dönemi uygulanmıştır. Daha sonra yapay yonca merasına başarı ile adaptasyonları sağlanan ineklerden çalışma süresi olarak belirlenen beş hafta boyunca süt örnekleri toplanmıştır. Süt örnekleri araştırma süresi boyunca haftada bir gün, sabah ve akşam sağımlarından alınmıştır. Sağımlardan alınan süt örnekleri 50 ml'lik tüplere alınarak, soğuk zincirle çalışmanın yapılacağı laboratuvara ulaştırılmıştır. Çalışma yapılacak süt örnekleri $+40^{\circ} \mathrm{C}^{\prime}$ de ön 1sıtmaya tabi tutulduktan sonra hafifçe karıştırılmıştır. Süt yağ asitlerinin analizi için ayrılan süt örnekleri analiz yapılacağı güne kadar -50 C'de muhafaza edilmiştir.

\subsection{Meranın otlatma kapasitesinin belirlenmesi}

Yapay yonca merasında hayvan beslemenin yaygin olarak yapıldığı Arjantin gibi tropik iklim bölgelerindeki ülkelerinin kullandığı model (Cangiano, Castillo, Guerrero, \& Putnam, 2008) bu çalışmada modifiye edilip, kış dönemine uyarlanarak yapılmıştır. Öncelikle çalışmada yer alan ineklerin günlük besin ihtiyaçları belirlenmiştir. Pratik olarak günlük kuru madde ihtiyacının yarısını meradan yarısını da ahıra döndüğünde padoktaki kesif yemle karşılanabilecek şekilde hesaplanmıştır. Daha sonra meranın yonca yoğunluğu ve meradan faydalanma oranı, bir dekar arazide yaş halde bulunabilecek yonca ağırlığı hesaplanarak yapılmıştır. Öncelikle hayvanların günlük kuru madde (KM) ihtiyaçları belirlenmiştir. Yonca ekili 
meralarda inekler iki haftalık bir adaptasyon uygulamasından sonra tüm gün merada otlamaya başlatılmışlardır (Sucak, Kara, Özkaya, Şahan, \& Serbester, 2016).

Tablo 1. Rasyon İçerikleri \%KM ve Kimyasal içerikleri Table 1. Contents of Ratio \% DM and Chemical Compositions

\begin{tabular}{lcc}
\hline Rasyon İçerik & $\begin{array}{c}\text { TMR Grubu } \\
(\%) ~ K M\end{array}$ & $\begin{array}{c}\text { Yonca Grubu } \\
(\%) K M\end{array}$ \\
\hline Arpa & 9.7 & 21 \\
21 Protein Ticari Yem & 41.2 & 31.2 \\
Yonca Yaş & ---- & 43.6 \\
Saman & 9.9 & 3 \\
Silaj & 28.9 & ---- \\
Kuru Yonca Otu & 9.5 & --- \\
Toplam & 100 & 100 \\
\hline Kuru Madde Tüketimi $\mathrm{Kg} / \mathrm{KM}$ & 18.7 & 19 \\
\hline Kimyasal Kompozisyonu & & \\
Kuru Madde $(\%)$ & 55.6 & 57.3 \\
Ham Protein & 15.4 & 17.8 \\
Ruphp'nin & 26.2 & 20.5 \\
Ham Selüloz & 18.6 & 16.1 \\
ADF & 20.5 & 20.7 \\
NDF & 34.8 & 32 \\
NEL & 1.09 & 0.95 \\
CA & 1 & 1.6 \\
P & 0.4 & 0.4 \\
K & 1.7 & 2 \\
Zn $(m g / k g)$ & 12.5 & 16.7 \\
\hline
\end{tabular}

Kış şartlarında yapay merada yonca miktarının az olmasına rağmen kuru madde oranı \%18 olarak ölçülmüştür. Hayvanlar parsellere birakılmadan önce meranin ot yoğunluğunun tespiti, hayvanların bırakılacağı parselin üç ayrı noktasından her biri $1 \mathrm{~m}^{2}$ olan alanlardan toplanan, yaş haldeki yoncaların ölçümleri ile yapılmıştır. Ortalama 100$110 \mathrm{gr} / \mathrm{m}^{2}$ olarak belirlenen sonuçlar doğrultusunda, adaptasyon denemelerinde 2 dekar olarak kullanılan alanın, telef olan yonca miktarı da dikkate alınarak düzeltilmiştir. Düzenleme sonucunda, yapay yonca merası her biri $600 \mathrm{~m}^{2}$ olan alanlarla, düşük voltajlı elektrikli teller yardımıyla parsellere ayrılmıştır. Bu ayrılan parsellerin her biri günlük 12 adet ineğin besleneceği mera olarak düzenlemiştir. Böylece, Yonca Grubu hayvanların beslenmesinde hayvan başına ortalama $9 \mathrm{~kg}$ kuru madde alımının yapay yonca merasından karşılanması sağlanmıştır.

\subsection{Kullanılan kimyasallar}

Kullanılan tüm kimyasallar analitik saflıktadır. Hekzan, sülfirik asit $\left(\mathrm{H}_{2} \mathrm{SO}_{4}\right)$, nitrik asit $\left(\mathrm{HNO}_{3}\right)$, izopropil alkol ve metanol Merck'ten satın alındı.

\subsection{Mineral analizi}

Süt numuneleri ( $3 \mathrm{ml})$ ve yonca bitkisi $(0.5 \mathrm{gr})$, mikrodalga çözme sisteminin DAP60-K PTFE kaplarına aktarılmıştır ve $5 \mathrm{ml} \mathrm{HNO}_{3} \quad(\% 65$ a/h)ilave edilmiştir. Çözünmüş numuneler $20 \mathrm{ml}$ balon jojelere aktarılmıştır. $0.1 \mathrm{M} \mathrm{HNO}_{3}$ ile son hacme kadar tamamlanmıştır. Kör numuneler aynı şekilde hazırlanmıştır. Çözeltiler ICP-MS cihazında analizleri yapılmıştır (Şahin et al.,2018). ICP-MS cihazında kalsiyum (Ca), demir (Fe), mangan (Mn), fosfor $(\mathrm{P})$ ve çinko (Zn) mineral madde düzeyleri tespit edilmiştir.

\subsection{Yağ asidi analizi}

$5 \mathrm{ml}$ süt numunesi hekzan/isopropanol (3:2 h/h) karışımı içerisinde homojenize edilmiştir. Lipit ekstraktları $5000 \mathrm{rpm}$ devirde 5 dakika santrifüj edilmiştir. Çözücüler $40^{\circ} \mathrm{C}^{\prime}$ de uzaklaştırılmıştır (Hara \& Radin, 1978). Lipit ekstraktlarındaki yağ asitleri metanol/sülfürik asit \%2'lik (h/h) $5 \mathrm{ml}$ ile metil esterlerine dönüştürülmüştür. Oluşan yağ asidi metil esterleri $5 \mathrm{ml}$ hekzan ile ekstrakte edilmiştir (Christie, 1989). Yağ asitleri gaz kromatografisi (Alev iyonizasyonu detektörlü SHIMADZU GC 2025) ile TR-CN 100 kapiler kolonu (60 m x $0.20 \mathrm{~mm}$ iç çap ve $25 \mu \mathrm{m}$ film kalınlığı) kullanılarak analiz edilmiştir. Her numune için üç tekrar ölçüm alınmıştır.

Yağ asitlerinin ve trans izomerlerin belirlenmesinde, örneklerdeki yağ asit metil esterleri piklerinin çıma süreleri ve pik alanlarının standartlarla karşılaştırılarak yapıldı. Linoleik asitin (18:2n6c) konjuge metil esteri (cis-9, trans-11 ve trans-10, cis-12-oktadekadienoik asit metil esterlerin karışımı, katalog numarası O5632) SigmaAldrich'ten (St Louis, MO, ABD) satın alınmıştır. Sonuçlar yüzde olarak ifade edilmiştir. Rapor edilen her sonuç, üç GC analizinin ortalama değeridir. Sonuçlar ortalama $(X)$ ve standart hata $( \pm$ SE $)$ olarak sunulmaktadir. Yonca bitkisinden 0.5 gr alınarak yukarıda belirtilen kimyasal işlemler yapılarak yă̆ asit düzeyleri tespit edilmiştir. Hesaplamalar GC Solutions 2.42 programı kullanılarak gerçekleştirilmiştir.

\section{6. İstatistiksel analiz}

Grupların yağ asitleri ve mineral düzeyleri karşılaştırılmasında bağımsız değişkenlerde $T$ testi ile yapıldı. Sonuçlar ortalama $(X)$ ve standart hata $( \pm S E)$ olarak belirtilmiştir.

\subsection{Etik kurul izin belgesi}

Çalışmanın etik kurul izin belgesi, Adıyaman'da faaliyet gösteren Vetal Hayvan Sağlığı Ürünleri A.Ş.'nin düzenlemiş olduğu 01.06.2015 tarihli ve 2015/1-1 Karar No'lu kararı ile alınmıştır.

\section{Sonuçlar ve Tartışma}

Yonca bitkisi mineral düzeyleri Tablo 2'de belirtilmiştir. Yonca bitkisi kalsiyum (Ca) $8167 \mathrm{mg} / \mathrm{kg}$, fosfor (P) 951 $\mathrm{mg} / \mathrm{kg}$, manganez $(\mathrm{Mn}) 14.16 \mathrm{mg} / \mathrm{kg}$, çinko (Zn) 4.25 $\mathrm{mg} / \mathrm{kg}$ ve demir $(\mathrm{Fe}) 143 \mathrm{mg} / \mathrm{kg}$, olarak tespit edilmiştir.

Tablo 2. Yonca bitkisi mineral düzeyleri (mg kg-1) Table 2. Mineral levels of Alfalfa (mg kg-1)

\begin{tabular}{cc}
\hline Mineraller & $\mathrm{X} \pm \mathrm{SE}$ \\
\hline $\mathrm{Ca}$ & $8167 \pm 54$ \\
$\mathrm{P}$ & $951 \pm 75$ \\
$\mathrm{Mn}$ & $14.16 \pm 1.2$ \\
$\mathrm{Zn}$ & $4.25 \pm 0.24$ \\
$\mathrm{Fe}$ & $143 \pm 19.28$ \\
\hline
\end{tabular}

Yonca bitkisi yağ asit düzeyleri Tablo 3'te verilmiştir. Yonca bitkisi önemli yağ asitlerinden stearik asit (18:0) $\% 29.788$, palmitik asit (16:0) \%9.551, alfa-linolenik asit (18:3n3) \%14.482 ve linoleik asit (18:2n6c) \%4.528 majör yăg asitleri olarak belirlenmiştir. Yonca bitkisi toplam doymuş yağ asit ( $($ SFA) düzeyi \%44.204, toplam doymamış yağ asit düzeyi ( $(U S F A)$ düzeyi \%21.323, toplam tekli doymamış yağ asit (¿MUFA) düzeyi \%2.162 ve çoklu doymamış yağ asit ( PUFA) düzeyi \%19.161 olarak tespit edilmiştir. Ayrıca, myristik asit (14:0) \%0.943, lignoserik asit (24:0) $\% 0.421$, palmitoleik asit (16:1) \%1.123, oleik asit (18:1n9c) 0.884 ve araşidik asit (20:0) \%0.961 düzeylerinde tespit edilmiştir. Ayrıca, yonca bitkisi içeriğinde toplam \%34.473 düzeyinde tanımlanmamış yağ asit düzeyi belirlenmiştir. 
Tablo 3. Yonca bitkisi yağ asit düzeyi (\%)

Table 3. Fatty acids levels of Alfalfa (\%)

\begin{tabular}{|c|c|c|c|c|c|}
\hline SFA & $X \pm S E$ & PUFA & $X \pm S E$ & MUFA & $\mathrm{X} \pm \mathrm{SE}$ \\
\hline $6: 0$ & $0.468 \pm 0.02$ & $18: 2 \mathrm{n} 6 \mathrm{c}$ & $4.528 \pm 0.25$ & $16: 1$ & $1.123 \pm 0.02$ \\
\hline 10:0 & $0.154 \pm 0.01$ & 18:3n6 & $0.044 \pm 0.31$ & $18: \ln 9 c$ & $0.884 \pm 0.04$ \\
\hline $12: 0$ & $0.350 \pm 0.03$ & $18: 3 n 3$ & $14.482 \pm 0.06$ & $20: 1 n 9 c$ & $0.063 \pm 0.01$ \\
\hline $13: 0$ & $0.074 \pm 0.001$ & $20: 3 n 3$ & $0.107 \pm 0.02$ & $24: 1$ & $0.092 \pm 0.03$ \\
\hline $14: 0$ & $0.943 \pm 0.03$ & $\sum$ PUFA & $19.161 \pm 1.19$ & $\sum$ MUFA & $2.162 \pm 0.05$ \\
\hline $15: 0$ & $0.134 \pm 0.02$ & & & & \\
\hline $16: 0$ & $9.551 \pm 0.15$ & & & & \\
\hline $17: 0$ & $0.151 \pm 0.02$ & & & & \\
\hline 18:0 & $29.788 \pm 0.55$ & & & & \\
\hline $20: 0$ & $0.961 \pm 0.01$ & & & & \\
\hline $22: 0$ & $0.640 \pm 0.02$ & & & & \\
\hline 23:0 & $0.589 \pm 0.15$ & & & & \\
\hline 24:0 & $0.401 \pm 0.02$ & & & & \\
\hline$\sum \mathrm{SFA}$ & $44.204 \pm 0.92$ & & & & \\
\hline$\sum$ USFA & $21.323 \pm 0.58$ & & & & \\
\hline Tanımlanmış Yağ Asit Düzeyi Toplamı & 65.527 & & & & \\
\hline Tanımlanmamış Toplam Yağ Asit düzeyi & 34.473 & & & & \\
\hline
\end{tabular}

Tablo 4. TMR ve Yonca grubu inek sütleri mineral düzeyleri (mg L-1)

Table 4. Milk Mineral Levels Milks of TMR and Yonca Groups (mg L-1)

\begin{tabular}{ccc}
\hline Elementler & X \pm SE(TMR Grubu) & $X \pm S E(Y o n c a ~ G r u b u)$ \\
Ca & $1115 \pm 52$ & $1282 \pm 68^{\mathrm{a}}$ \\
$\mathrm{P}$ & $961 \pm 40$ & $1162 \pm 58^{\mathrm{a}}$ \\
$\mathrm{Mn}$ & $0.019 \pm 0.0012$ & $0.017 \pm 0.0013$ \\
$\mathrm{Fn}$ & $1.701 \pm 0.086$ & $2.164 \pm 0.104^{\mathrm{a}}$ \\
\hline
\end{tabular}

a: $\mathrm{p}<0.05$, b: $\mathrm{p}<0.01, \mathrm{c}: \mathrm{p}<0.001$

Tablo 5. TMR ve Yonca grubu inek sütleri yă asit düzeyleri (\%)

Table 5. Milk Fatty Acids Levels Milks of TMR and Yonca Groups (\%)

\begin{tabular}{|c|c|c|}
\hline Yağ Asitleri & 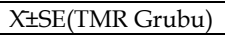 & $\mathrm{X} \pm \mathrm{SE}($ Yonca Grubu) \\
\hline $06: 0$ & $0.59 \pm 0.02$ & $0.54 \pm 0.03$ \\
\hline 08:0 & $1.38 \pm 0.09$ & $1.04 \pm 0.05^{b}$ \\
\hline $10: 0$ & $0.31 \pm 0.27$ & $0.35 \pm 0.04$ \\
\hline $12: 0$ & $0.30 \pm 0.12$ & $1.26 \pm 0.35^{c}$ \\
\hline 13:0 & $5.13 \pm 1.16$ & $5.55 \pm 1.10$ \\
\hline $14: 0$ & $14.90 \pm 0.16$ & $10.91 \pm 0.39 c$ \\
\hline $15: 0$ & $0.41 \pm 0.02$ & $0.97 \pm 0.09 \mathrm{~b}$ \\
\hline $16: 0$ & $29.01 \pm 0.51$ & $27.98 \pm 0.41$ \\
\hline $18: 0$ & $12.43 \pm 0.27$ & $13.28 \pm 0.21$ \\
\hline $22: 0$ & $1.06 \pm 0.09$ & $1.59 \pm 0.24$ \\
\hline $24: 0$ & $0.64 \pm 0.02$ & $0.85 \pm 0.02$ \\
\hline$\Sigma$ SFA & $66.16 \pm 2.04$ & $64.32 \pm 1.98$ \\
\hline $14: 1$ & $0.66 \pm 0.02$ & $0.82 \pm 0.06^{\mathrm{a}}$ \\
\hline $16: 1$ & $1.51 \pm 0.09$ & $1.62 \pm 0.08$ \\
\hline $18: \ln 9 \mathrm{c}$ & $23.95 \pm 0.47$ & $24.23 \pm 0.57$ \\
\hline $20: 1 n 9 c$ & $0.33 \pm 0.03$ & $0.72 \pm 0.05^{c}$ \\
\hline$\Sigma$ MUFA & $26.45 \pm 1.12$ & $27.39 \pm 1.18$ \\
\hline $18: 2 \mathrm{~N} 6 \mathrm{c}$ & $3.26 \pm 0.18$ & $3.71 \pm 0.29$ \\
\hline $18: 3 \mathrm{n} 6$ & $0.34 \pm 0.02$ & $0.57 \pm 0.03^{a}$ \\
\hline $20: 3 n 6$ & $0.56 \pm 0.04$ & $1.01 \pm 0.15^{\mathrm{a}}$ \\
\hline $20: 5 \mathrm{n} 3$ & $0.46 \pm 0.06$ & $0.69 \pm 0.07 \mathrm{a}$ \\
\hline $22: 6$ & $2.24 \pm 0.11$ & $1.60 \pm 0.16^{\mathrm{a}}$ \\
\hline$\Sigma$ PUFA & $7.39 \pm 0.49$ & $7.58 \pm 0.52$ \\
\hline$\Sigma$ USFA & $33.84 \pm 1.24$ & $34.97 \pm 1.35$ \\
\hline KLA c9t11 & $0.37 \pm 0.01$ & $0.45 \pm 0.02^{\mathrm{a}}$ \\
\hline KLA t10c12 & $0.16 \pm 0.01$ & $0.26 \pm 0.01^{a}$ \\
\hline$\Sigma$ CLA & $0.53 \pm 0.03$ & $0.71 \pm 0.04^{\mathrm{a}}$ \\
\hline
\end{tabular}

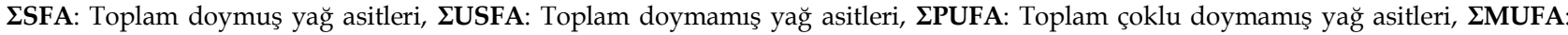
Toplam tekli doymamıs yağ asitleri; $\boldsymbol{\Sigma}$ CLA: Toplam KLA

TMR Grubu ve Yonca Grubu ineklerin süt mineral düzeyleri Tablo 4'te verilmiştir. TMR Grubu ineklerin süt minerallerinden $\mathrm{Ca}, \mathrm{P}, \mathrm{Mn}, \mathrm{Z}$ ve Fe sirası ile $1115 \mathrm{mg} \mathrm{L}-1$, $961 \mathrm{mg}$ L-1, $0.019 \mathrm{mg}$ L-1, n $1.701 \mathrm{mg} \mathrm{L-1}$ ve $0.582 \mathrm{mg} \mathrm{L-1}$ olarak belirlenmiştir. Diğer yandan, Yonca Grubu inek sütü minerallerinden $\mathrm{Ca}, \mathrm{P}, \mathrm{Mn}, \mathrm{Zn}$ ve Fe sirası ile $1282 \mathrm{mg} \mathrm{L}-1$, $1162 \mathrm{mg} \mathrm{L}-1,0.017 \mathrm{mg} \mathrm{L}-1,2.164 \mathrm{mg} \mathrm{L}-1$ ve $0.557 \mathrm{mg} \mathrm{L}-1$ olarak belirlenmiştir. Yonca Grubu'nun süt minerallerinden $\mathrm{Ca}, \mathrm{P}$ ve Zn düzeylerinin TMR Grubu'na göre yükssek çıktığı tespit edilmiştir $(\mathrm{p}<0.05)$.

TMR Grubu ve Yonca Grubu inek sütleri yă̆ asit düzeyleri Tablo 5'te verilmiştir. TMR Grubu 14:0 yağ asit düzeyi Yonca Grubu'na göre yüksek çıtığı tespit edilirken ( $\mathrm{p}<0.001), 16: 0$ yağ asit düzeyleri TMR Grubu'nda nispi olarak yüksek çıktığı belirlenmiştir ( $p>0.05)$. Yonca Grubu doymamış yağ asitlerinden myristoleik asit (14:1), cis-11Eikosenoik asit (20:1n9c), gamma-linolenik asit (18:3n6), cis8,11,14-Eicosatrienoik asit(20:3n6), cis-5,8,11,14,17Eicosapentaenoik asit (20:5n3), konjugelinoleik asit (KLA) c9t11 ve KLA t10c12düzeyleri TMR Grubu'na göre yüksek çıtığı saptandı $(\mathrm{p}<0.05)$. TMR Grubu $\sum \mathrm{SFA}, \sum \mathrm{USFA}$, $\sum$ MUFA ve $\sum$ PUFA sirasi ile \%66.16, \%33.84, \%26.45 ve $\% 7.39$ oranında olduğu tespit edildi. Yonca Grubu'nda ise 
$\sum$ SFA, $\sum$ USFA, $\sum$ MUFA ve $\sum$ PUFA sirasi ile \%64.32, \%34.97, $\% 27.39$ ve $\% 7.58$ oranında olduğu tespit edildi.

\section{Sonuç ve Öneriler}

$\mathrm{Bu}$ çalışmada, kış döneminde TMR Grubu ve Yonca Grubu'ndaki ineklerin laktasyon dönemlerinde alınan sütlerinde, süt mineralleri ve süt yağ asit düzeyleri tespiti yapılarak, yonca bitkisinin bu parametrelere etkinliği araştırılmıştır. Araştırmamızda, yapay yonca merasında beslenen Yonca Grubu ineklerin süt $\mathrm{Ca}, \mathrm{P}$ ve $\mathrm{Zn}$ düzeyleri, TMR ile beslenen TMR Grubu ineklerin sütlerine göre yüksek çıktığı tespit edilmiştir. Yem içeriğindeki mineral düzeyleri hayvan beslenmesinde çok önemlidir (NRC, 2001).

Hayvancılıkta otlatmanın amaçlarından bir tanesi de taze otlardan mineral gereksinimlerinin karşılaması olduğu için hayvanlara verilecek yemlerin mineral değerleri bakımından özelliği ön plana çıkmaktadır (Espinoza, Mcdowell, Wilkinson, Conrad, \& Martin, 1991).Yemlerdeki mevcut mineral düzeyleri kullanılan yem bitkisinin yetiştirildiği toprak özelliğine, yem bitkisi türüne ve işletme faktörlerine bağlı olarak değiştiği gözlenmektedir. Hayvanların beslenmesinde akut ve kronik mineral eksikliği ciddi anlamda metabolik bozukluklara ve hayvansal üretim yetersizliğine yol açmaktadır (Pinchak, Greene, \& Heitschmidt, 1989). Ruminantların otlatılarak beslenmesinde $\mathrm{Ca}, \mathrm{P}, \mathrm{Cu}$ ve $\mathrm{Zn}$ mineralleri bakımından zengin hayvansal ürünler elde edilebilmektedir (McDowell, 1996). Hayvan yemlerinde mineral içeriği bakımından en zengin bitkiler arasında yonca bulunmaktadır. Bu açıdan incelendiğinde hayvancılı̆̆ın mineral taleplerini karşılayan en önemli yem bitkileri içerisinde yonca da yer almaktadır (Markovic, Strbanovic, Cvetkovic, Andelkovic, \& Zivkovic, 2009). Sütün biyokimyasal içerikleri üzerine en önemli etkilerinden biri de hayvanların beslenme durumları ve şartlarıdır (Kalac \& Samkova, 2010). Bu çalışmada, literatürlerde belirtildiği gibi hayvan beslenmesinde en önemli minerallerden olan $\mathrm{Ca}$, $\mathrm{P}$ ve $\mathrm{Zn}$ düzeylerinin Yonca Grubu ineklerin sütlerinde artışı tespit edilmiştir. Yonca bitkisi $\mathrm{Ca}, \mathrm{P}, \mathrm{Zn}, \mathrm{Cu}$ ve $\mathrm{Mn}$ mineralleri bakımından zengindir. Özellikle de Ca ve P düzeyleri bakımında zengin olduğu da rapor edilmiştir (Markovic, Strbanovic, Cvetkovic, Andelkovic, \& Zivkovic, 2009). Çalışmamızda, yoncanın süt içeriğindeki mineral düzeylerine pozitif katkıda bulunduğunu düşünmekteyiz.

TMR Grubu'nda $\sum$ SFA, $\sum$ USFA, $\sum$ MUFA ve $\sum$ PUFA siras1 ile $\% 66.16, \% 33.84, \% 26.45$ ve $\% 7.39$ olarak tespit edilmiştir. Yonca Grubu'nda ise $\sum$ SFA, $\sum$ USFA, $\sum$ MUFA ve $\sum$ PUFA sirası ile \%64.32, \%34.97, \%27.39 ve \%7.58 oraninda gözlenmiştir. TMR Grubu'nda majör yağ asitlerinden 14:0, 16:0, 18:0 ve 18:1n9c yağ asitleri sırası ile \%14.90, \%29.01, $\% 12.43$ ve $\% 23.95$ düzeylerine bulunurken, Yonca Grubu'nda bu majör yağ asitlerinin düzeyleri sırası ile $\% 10.90, \% 27.98, \% 13.28$ ve $\% 24.23$ olarak tespit edilmiştir. TMR Grubu'nda özellikle 14:0 yağ asit düzeyi Yonca Grubu'na göre önemli düzeyde fazla çıktığı gözlenmiştir. Ayrıca 16:0 düzeyi ise TMR Grubu'nda nispi oranda fazla çıktığı görülmektedir. Bu durum, TMR Grubu'ndaki $\sum$ SFA düzeyinin de artmasına neden olmuştur. TMR Grubu tekli doymamış yağ asit düzeyleri (14:1, 16:1, 18:1n9c ve 20:1n9c) genel olarak Yonca Grubu'na oranla düşük olduğu tespit edilmiştir. Ayrıca TMR Grubu, çoklu doymamış yağ asitlerinden 18:3n6, 20:3n6, 20:5n3 düzeyleri Yonca
Grubu'na oranla daha az çıtığı belirlenmiştir. Bu sonuçlar ışığında, tekli ve çoklu yağ asit bileşenlerin Yonca Grubu inek sütlerinde yüksek çıkması yonca bitkisinin ineklerde süt yağ asitleri metabolizmasını etkilediğini düşünmekteyiz. Ayrıca, doymamış yağ asitlerinin insan metabolizması üzerine birçok pozitif etkileri olduğu bilinmektedir. Özellikle çocuklarda sağlıklı gelişimi sağladığı ve beyinsel gelişimlerini artırdığı ayrıca koroner kalp hastalık riskini azalttığı rapor edilmiştir (Cao, Yu, Wang, Wang, \& Lei, 2013; Mensink, Zock, Kester, \& Katan, 2003; Harris, Kris-Etherton, \& Harris, 2008; Bemelmans et al., 2002). Hayvan beslenmesi yönünden, yonca bitkisinin yă̆ asit düzeyleri incelendiğinde, metabolizma açısından çok önemli yağ asitlerinin yüksek düzeyde olduğu bu çalışma sonuçları ile belirlenmiştir. Yonca içeriğindeki majör yağ asitlerinden 16:0, 18:0, 18:2n6c ve 18:3n3 düzeyleri sırası ile \%9.551, \%29.788, \%4.528 ve \%14.482 olarak tespit edilmiştir. Bu sonuçlar açısından değerlendirildiğinde, yonca bitkisinin doymuş ve doymamış yağ asitleri yönünden zengin olduğu görülmektedir. Yonca bitkisi içeriğindeki bu yağ asitlerinin, ineklerin beslenmesinde önemli düzeyde katkı sağladığını düşünmekteyiz. Ayrıca, bu çalışmada, yonca bitkisi içeriğinde toplam \%34.473 düzeyinde tanımlanmamış yağ asit düzeyi de belirlenmiştir. Yonca bitkisi üzerinde bu alanda yapılacak sonraki bilimsel çalışmalarda, tanımlanmamış \%34.473 düzeyindeki yă̆ asitlerin neler olduklarının belirlenmesi araştırılabileceği gibi tanımlanacak bu yağ asitlerinin ineklerin beslenmesindeki rollerinin aydınlatılması konuları ele alınabilir.

Çalışmada en önemli sonuçlardan biri de Yonca Grubu KLA c9t11 ve KLA t10c12 yă̆ asitleri düzeyleri bakımından TMR Grubu'na göre yüksek çıkması olmuştur. KLA, özellikle geviş getiren hayvanların Rumenlerinde enzimatik reaksiyonlar sonucunda izomerleri şeklinde sentezlenmektedir. En fazla oranda sentezlenen cis-9, trans11 izomeridir. Insanlar KLA ihtiyacının \%60'nı süt ürünlerinden, \%37'sini et ürünlerinden karşılamakla birlikte, alınan KLA içeriğinde en fazla oranda cis- 9, trans11 KLA izomeri olduğu rapor edilmiştir (Wang \& Jones, 2004). Hayvanların et ve süt ürünlerinde bulunan KLA'nın insan metabolizmasına birçok pozitif etkileri bildirilmiştir (İnanç, 2006; Wahle, Heys, \& Rotondo, 2004; Tanaka, 2005; Kurban \& Mehmetoğlu, 2006; Sezer, Aksoy, Üstün, \& Tüter, 2011; Yücel, Özçimen, \& Tatlı, 2011; Kelly, 2001). KLA üretimi hayvanların rumenlerinde gerçekleşmektedir. Hayvan beslenmesinde bitkisel yağlar ve yağlı tohumlarla takviye edilmesi durumunda KLA'nın arttığı bildirilmiştir. Merada beslenen ineklerle normal şartlarda rasyonla beslenen ineklerin sütlerindeki KLA düzeyleri karşılaştırıldığında, merada beslenen ineklerin süt yağında yüksek düzeyde KLA içeriği gözlemlenmiştir (Schroeder et al., 2003).

Taze otlarla beslenen hayvanların süt içeriğinde KLA yağlarının yüksek çıkma nedeni bu otlarda yüksek düzeyde linoleik ve alfa-linolenik asitlerin düzeyinin yüksek olmasından kaynaklandığı bildirilmiştir (Izumi, An, Kobayashi, \& Tanaka, 2002).

Çalışmamızda, yonca bitkisi içeriğindeki 18:2n6cn yağ asiti oranı \%4.528 düzeyinde çıktığ Literatürde 18:3n3 ve18:2n6c yağ asiti içerikli otların ineklerin süt KLA düzeyini artırdığı belirtilmiştir (Izumi, 
An, Kobayashi, \& Tanaka, 2002). Ayrıca, yonca bitkisi içeriğindeki 22 adet yağ asiti düzeylerinin tespitinin bu çalışmada yapılmış olmasının, yonca bitkisi üzerine bu konuda yapılmış diğer çalışmalardan önemli derecede farklılaştığını ortaya koymaktadır. Bu farklılığın, önceki çalışmalardaki kullanılan GC cihazının özellikleri ve kullanılan yağ asit standartlarının niteliğinden kaynaklandığını düşünmekteyiz. Literatürde, taze yonca bitkisi yağ asit düzeyi çalışmasında 5 adet olan 16:0,18:0, 18:1, 18:2 ve 18:3 yağ asitlerinin düzeyleri sirası ile $\% 20.8$, \%3.40, \%2.65, \%17 ve \%48.6 olarak tespit edilmiştir (Ribeiro, Karnati, \& Eastridge, 2005).

Bir önceki çalışmamızda laktasyon dönemindeki ineklere verilen yoncanın süt verimi ve kompozisyonu, vücut kondisyon skoruna pozitif etki gösterdiği tespit edilmiştir (Sucak et al., 2016). Bu çalışmada süt içeriğinde araştırılan 18:2n6c izomerleri olan KLA türleri tespiti yapılmıştır. Ancak, 18:3n3 yağ asidinin KLA metabolizmasında izomerleri olan yağ asitleri tespiti yapılamamıştır. İleriki çalışmalara yonca bitkisi içeriğindeki yüksek düzeyde tespit ettiğimiz 18:3n3 yağ asidinin rumende biyohidrejenasyon dönüşümündeki KLA tespit çalışmalarına etkili olabileceğini düşünmekteyiz.

Sonuç olarak, kış döneminde taze yonca içeriği ile beslenen ineklerin süt minerallerinden $\mathrm{Ca}, \mathrm{P}, \mathrm{Zn}$, doymamış yağ asitleri ve KLA yağ asit düzeylerine pozitif düzeyde etkileri olduğunu düşünmekteyiz.

Teşekkür: Bu çalışma Adıyaman Üniversitesi Bilimsel Araştırma Koordinasyon Birimi tarafından KMYOMAP/2015-0002 numaralı proje ile desteklenmiştir.

\section{Kaynaklar}

Appel, L.J., Miller, E.R., Seidler, A.J., \& Whelton, P.K. (1993). Does supplementation of diet with "fish oil" reduce blood pressure? A metaanalysis of controlled clinical trials. Archives of Internal Medicine, 153(12), 1429-1438.

Bemelmans, W.J.E., Broer, J., Feskens, E.J.M., Smit, A.J., Frits, A.M.J., Lefrandt, J.D.,... Jong, B.M., (2002). Effect of an increased intake of alinolenic acid and group nutritional education on cardiovascular risk factors: the Mediterranean Alpha-linolenic Enriched Groningen Dietary Intervention (MARGARIN) study. The American Journal of Clinical Nutrition, 75(2), 221-227.

Cangiano, C.A., Castillo, A.R., Guerrero, J.N., \&Putnam, D.H. (2008). Alfa Grazing Management, Irrigated Alfalfa Management for Mediterranean and Desert Zones. University of California, Division of Agricultural and Natural Resources, Publication 8304 (2), Chapter 18

Cao, A.H, Yu, L., Wang, Y.W., Wang, G.J., \&Lei, G.F, (2013). Composition of long chain polyunsaturated fatty acids (LC-PUFAs) in different encephalic regions and its association with behavior in spontaneous hypertensive rat (SHR). Brain Research, 1528, 49-57.

Castillo, A.R., Taverna, M.A., Aaez, P. R., Catrın, A., Colombatto, D., Bargo, F., Drackley, J. K. (2006). Fatty acid composition of milk from dairy cows fed fresh alfalfa based diets. Animal Feed Science and Technology, $131,241-254$

Chaturvedi, U.C., Shrivasta, R., \& Upreti, R.K. (2004). Viral infections and trace element: a complex interaction. Current Science, 87(11), 1536-1554.

Christie, W.W. (1989). Gas chromatography and lipids: a practical guide. Ayr, Scotland, The Oily Press, 307 pp.

Claeys, W.L., Cardoen, S., Daube, G., Block, J.D., Dewettinck, K., Dierick, K., Herman, L. (2013). Raw or heated cow milk consumption: Review of risks and benefits, Food Control, (31), 251-262.

Claeys, W.L., Verraes, C., Cardoen, S., De Block, J., Huyghebaert, A., Raes, K., ... Herman, L. (2014). Consumption of raw or heated milk from different species: An evaluation of the nutritional and potential health benefits. Food Control, 42, 188-201.

De Lorgeril, M., Salen, P., Martin, J.L., Monjaud, I., Delaye, J., \& Mamelle, N. (1999). Mediterranean diet, traditional risk factors, and the rate of cardiovascular complications after myocardial infarction. Final report of the lyon diet heart study. Circulation, 99(6), 779-785.

Emsley, J. (2011). Nature's building blocks: an A-Z guide to the elements. Oxford, UK, Oxford University Press, 699 pp.

Espinoza, J.E., Mcdowell, L.R., Wilkinson, N.S., Conrad, J.H., \&Martin, F.G. (1991). Forage and soil mineral concentrations over a 3 years period in a warm climate region of central Florida. II. Trace minerals. Livestock Research for Rural Development, 3(1), 3-10.

Hara, A., \& Radin, N.S. (1978). Lipid extraction of tissues with a low-toxicity solvent. Analytical Biochemistry, 90, 420-426.

Harris, W.S., Kris-Etherton, P.M., \& Harris, K.A. (2008). Intakes of longchain omega-3 fatty acid associated with reduced risk for death from coronary heart disease in healthy adults. Current atherosclerosis reports, 10(6), 503-9.

Izumi, Y., An, J.K., Kobayashi, Y., \&Tanaka, K. (2002). Effects of fresh grass feeding on the formation of conjugated linoleic acid (CLA) and vaccenic acid (trans-11C18:1) in the rumen. Proceedings of Japanese Society for Rumen Metabolism and Physiology, 15, 43-46.

İnanç, N. (2006). Konjuge linoleik asit: obezitede etkileri. Sağlık Bilimleri Dergisi, 15(2), 137-141.

Kalac, P., \& Samkova, E. (2010). The effects of feeding various forages on fatty acid composition of bovine milk fat: A review. Czech Journal of Animal Science, 55(12), 521-37.

Kelly, G.S. (2001). Conjugated linoleic acid: a review. Alternative Medicine Review, 6(4), 367-82

Kurban, S., \& Mehmetoğlu, İ. (2006). Konjuge linoleik asit metabolizması ve fizyolojik etkileri. Türk Klinik Biyokimya Dergisi, 4(2), 89-100.

Li, D., \& Hu, X. (2009). Fish and its multiple human health effects in times of threat to sustainability and affordability: are there alternatives? Asia Pacific Journal of Clinical Nutrition, 18(4), 553-563.

Markovic, J., Strbanovic, R., Cvetkovic, M., Andelkovic, B., \& Zivkovic, B. (2009). Effects of Growth Stage on the Mineral Concentrations in Alfalfa (Medicago sativa L.) Leaf, Stem and the Whole Plant. Biotechnology in Animal Husbandry, 25(5-6), 1225-1231.

Mcdowell, L.R. (1996). Feeding minerals to cattle on pasture. Animal Feed Science and Technology, 60, 247-271.

Mensink, R.P., Zock, P.L., Kester, A.D., \& Katan M.B. (2003). Effects of dietary fatty acids and carbohydrates on the ratio of serum total to HDL cholesterol and on serum lipids and apolipoproteins: a meta-analysis of 60 controlled trials. The American Journal of Clinical Nutrition, 77(5), 114655.

National Research Council (NRC). (2001). Nutrient Requirements of Dairy Cattle: Seventh Revised Edition, 2001. Washington, DC: The National Academies Press. https://doi.org/10.17226/9825.

Pereira, P.C. (2014). Milk nutritional composition and its role in human health. Nutrition, 30, 619-627.

Pinchak, W.E., Greene L.W., \& Heitschmidt, R.K. (1989). Mineral dynamics in beef cattle diets from a southern mixed-grass prairie. Journal of Range Management, 42(5), 431-433.

Ribeiro, C.V.D.M., Karnati, S.K.R., \& Eastridge, M.L. (2005). Biohydrogenation of Fatty Acids and Digestibility of Fresh Alfalfa or Alfalfa Hay Plus Sucrose in Continuous Culture. Journal of Dairy Science, 88(11), 4007-4017.

Sahin, Z., Ozkaya, A., Uckun, M., Yologlu, E., Kuzu, Comakli, V., Demirdag, R., Tel, A.Z., Aymelek, F.F., \& Yologlu, S. (2019). Evaluation of the effects of Cyclotrichium niveum on brain acetylcholinesterase activity and oxidative stress in male rats orally exposed to lead acetate. Cellular and Molecular Biology, 65(5), 3-8. doi: 10.14715/cmb/2019.65.5.2

Schroeder, G.F, Delahoy, J.E., Vidaurreta, I., Bargo, F., Gagliostro J.A., \& Muller, L.M. (2003). Milk fatty acid composition of cows fed a total mixed ration or pasture plus concentrates replacing corn with fat. Journal of Dairy Science, 86, 3237-3248.

Selvaraju, R., Raman, R.G., Narayanaswamy, R., Valliappan, R., \& Baskaran, R. (2009). Trace element analysis in hepatitis B affected human blood serum by inductively coupled plasma-atomic emission spectroscopy (ICP-AES). Romanian Journal of Biophysics, 19, 35-42.

Sezer, Ç., Aksoy, H.A., Üstün, G., \& Tüter, M. (2011). Incorporation of conjugated linoleic acid into corn oil: optimization by response surface methodology. s. 185. 9 $9^{\text {th }}$ Euro Fed Lipid Congress, 18-21 September, Rotterdam, Nederlands.

Steffens, W., \& Wirth, M. (2005). Fresh water fish-an important source of n3 polyunsaturated fatty acids: a review. Archives of Polish Fisheries, 13, 516. 
Sucak, M.G., Kara, U., Özkaya, A., Şahan, Z., \& Serbester, U. (2016). Laktasyondaki Süt İneklerinin Kış Sezonunda Yonca (Medicago sativa) ile Oluşturulmuş Yapay Merada ad libitum Beslenmesinin Süt Kompozisyonu, Kan Profili ve Üreme Faaliyetleri Üzerine Etkisi. 1. Uluslararası Hayvan Besleme Kongresi, 28 Eylül-1 Ekim 2016. Antalya, Türkiye, pp 331.

Tanaka, K., (2005). Occurrence of conjugated linoleic acid in ruminant products and its physiological functions. Animal Sci. J., 76, 291-303.

Volesky, J.D., \& Anderson, B.E., (2010). Grazing Alfalfa. Retrieved from http:// extensionpubs.unl.edu/publication/9000016367413/grazingalfalfa/

Wahle, K.W., Heys, S.D., \& Rotondo, D. (2004). Conjugated linoleic acids: are they beneficial or detrimental to health? Progress in Lipid Research, $43,553-587$.

Wang, Y., \& Jones, P.J., (2004). Dietary conjugated linoleic acid and body composition. The American Journal of Clinical Nutrition, 79, 1153-1158.

Yücel, S., Özçimen, D., \& Tatll, A., (2011). Benefical health effects of conjugated linoleic acids. s. 227. 9th Euro Fed Lipid Congress, 18-21 September, Rotterdam, Nederlands. 